\title{
Life Lines: Loss, loneliness and expanding meshworks with an urban Walk and Talk group.
}

People need other people. True independence - for everyone, well, or ill - is rooted in social connection; without this, it is mere isolation and loneliness. This deep need for connectedness is insufficiently acknowledged throughout the whole of our society [...] But the lack of it hits the mentally ill [sic] particularly hard since it is so often failures of social connection, particularly in early life, that cause such disorders [sic] in the first place. 'Recovery', if it is to happen, must address this (Taylor, 2014: 252-3).

Barbara Taylor, writing here in her memoir 'The Last Asylum' reflects on the differences between her own experiences of asylum care in the UK in the 1980s, and the current system. Critiquing the current British policy language of 'recovery' and 'choice', she argues against the idea that those using mental health services need to avoid 'dependency' at all costs. These ideas, Taylor argues, in line with survivor activist groups such as 'Recovery in the Bin' and 'Mental Health Resistance Network', have been used to cut support for people experiencing mental health difficulties, and also limit the quality and depth of relationships which can be fostered through and with mental health care. This includes the reduction of spaces where those experiencing distress can go and be with others, without having to engage in specific, time limited, professionally-led activities (Bloomfield \& McLean, 2003; Moriarty et al, 2007). McGrath \& Reavey (2016) characterise such an approach as a 'helicopter service', arguing that services have become more distant, short term, and individualised. Rather than leading to 'independence', Taylor argues that such atomised, de-spatialised and distancing services only compound experiences of isolation and loneliness central to many experiences of distress (Hawkley \& Cacioppo, 2010; Warner, 2000).

There is indeed ample evidence that loneliness and social isolation are important in the development of distress, and harmful to recovery (Hawkley \& Cacioppo, 2010; Warner, 2000). Hawkley \& Cacioppo (2010: 3) outline the substantial evidence that loneliness is causative of many forms of distress, stating that a "perceived sense of social connectedness serves as a scaffold for the self-damage the scaffold and the rest of the self begins to crumble". In addition, long term service use has also been found to sometimes entrench social isolation, compounded by experiences of stigma (Sayce, 2000), as well as social and economic exclusion (Rogers \& Pilgrim, 2014; Wickham, Taylor, Shevlin \& Bentall, 2014). These ongoing impacts can be seen in the fact that long term service users tend to have smaller social networks, which are more dependent on family, than those who are not service users (Estroff, 1981). Characteristic of long term distress and service use, therefore, can be a shrinkage of social networks and connections (Levitas, 2006; Rogers \& Pilgrim, 2014), often characterised as reduced 'social capital' (Putnam, 2001). Silva et al.'s (2005) systematic review indeed found an inverse relationship between social capital and levels of distress, both in terms of numbers of connections and the felt quality of those connections.

Compounding such experiences of social and economic exclusion are the spatial exclusions also faced by those experiencing distress. A body of literature in human geography (Parr, 2008; Davidson, 2000; Curtis, 2010) and social psychology (Smith \& Tucker, 2014; Tucker, 2010; 2013; McGrath \& Reavey, 2015; 2016) has mapped the hostility of public and everyday community spaces to those experiencing distress and crisis. These echo Goffman's (1963) classic argument that public space has more stringent rules of behaviour and emotional expression than private space. These limitations can lead to feelings of exclusion, judgement, shame and fear for people experiencing current distress, leading to further retreats to the home (McGrath \& Reavey, 2015; Davidson, 2000) or other safe private spaces (Pinfold, 2000). Knowles (2000: 221) similarly found that "remaining invisible is the price of using public space" for homeless service users trying to navigate hostile public spaces; whilst her participants were able to remain in consumerist public spaces, such as shopping malls, it was 
only on the proviso they did not attract the attention of other customers and discretely maintained a façade that they were partaking in ongoing consumption.

The shrinkage of space in mental health care described by Taylor above, therefore, can be seen to be compounded by further exclusions and difficulties in public space for mental health service users. This hostile landscape is, we argue, detrimental to the fostering of social connection needed for 'true independence' of a connected life, rather than the isolation and loneliness described by Taylor. If mental health services are to address the loneliness central to so much distress, we argue that holistic interventions are needed which address not only individual cognitions or biology, but the social, spatial and emotional assemblages of people's lives. To make this argument, we draw on the experiences of participants of a Walk and Talk group in an inner city urban environment, and propose an ecological framework for understanding and addressing distress in context.

\subsection{Ecological theory: Ingold's meshworks}

Ecological approaches posit that people are, at a fundamental level, organisms immersed in environments from which they cannot be separated (Bateson, 1972; Ingold, 2000; 2011; Gibson, 1977; Kelly, 2006; Lewin, 1926; Capra \& Luisi, 2014). Ingold (2011: 95) argues: "The environment is, in the first place, a world we live in, and not a world we look at. We inhabit our environment: we are part of it; and through this practice of habitation it becomes part of us too". This inter-relational perspective is influenced by process philosophy (see Whitehead, 1927), which challenges the bifurcation of nature into subject and object (Barad, 2007; Bennett, 2010). It highlights that understandings of individuals' subjectivities cannot be gained without a holistic consideration of the material and social contexts in which they live. An ecological ontology also proposes that life and living beings are never static but are always in process: "For minds and lives are not closed-in entities that can be enumerated and added up; they are open-ended processes" (Ingold, 2015: 11). Thus, humans, like other organisms, are characterised by processes of growth, becoming and movement that are intrinsically related to the world they inhabit. This focus on the processual nature of experience conveys that the relationships individuals form with their surroundings are never stable but constantly evolving.

A core concept emerging from this perspective is that everyday spaces function like systems that are dynamically shaped by forces including social-material conditions, events, memories and emotions, which interweave in complex ways to expand or contract subjective experience, to offer or shut down possibilities for action. Ingold (2011) uses the metaphor of line and wayfarer to convey the embodied experience of moving through and making interconnected places. He argues that the 'lines' individuals lay become knotted with those of others to form 'meshworks':

Proceeding along a path, every inhabitant lays a trail. Where inhabitants meet, trails are entwined, as the life of each becomes bound up with each other. Every entwining is a knot, and the more lifelines are entwined, the greater the density of the knot. Places, then, are like knots, and the threads from which they are tied are lines of wayfaring. A house for example, is a place where the lines of its residents are tightly knotted together. But these lines are no more contained within the house than are threads within a knot. Rather, they trail beyond it, only to be caught up with other lines in other places, as are threads in other knots. Together they make up what I have called the meshwork (Ingold, 2011: 149).

The 'meshwork' is here understood as the process of living with others, at once entangled together, located in particular, embodied, material locations, and yet still not wholly defined by that location, due to the unique paths which each person has forged through the world: 
This tangle is the texture of world [...] beings do not simply occupy the world, they inhabit it, and in so doing - in threading their own paths through the meshwork they contribute to the ever-evolving weave (Ingold, 2000: 66-7).

It is this sense of living in space as being characterised by a set of embodied activities with others, which we wish to expand in this paper. Human geographers, in particular, have offered understandings of space that challenge Euclidean conceptions of it as simply a container, in which things happen or are held (Hubbard \& Kitchin, 2010; Jones, 2009; Parr, 2008). Instead, space is viewed as in flux and interwoven with social, political and economic phenomena (Hubbard \& Kitchin, 2010). Massey (2005: 9) argues that space is recursively produced through heterogeneous "interactions, from the immensity of the global to the intimately tiny". Thus, people's subjectivities, and the everyday practices through which they express them, both produce and are produced by the manifold spaces through which they move (Valentine \& Sporton, 2009). Ingold's work further deepens this perspective by bringing to the fore the ways in which people grow together through shared relationships and activity. He emphasizes how through weaving our lives together, we constantly draw upon, use, make, and remake the material and relational substances of our environments.

In this way, an ecological perspective has resonance with other moves in psychological theory that emphasise the distributed and embodied nature of psychological properties, including cognition (Chemero, 2009), perception (Gibson, 1977) and emotion (Maiese, 2011). If the substances of the environments in which we live are active participants in constructing agency, action and feeling, then what does this mean for those living with long term experiences of distress, isolation and loneliness within the limited and hostile spaces described above? We might, through this framework, understand loneliness as a curtailed experience of meshwork, and envisage that a person who is socially isolated may have a meshwork with less activity, growth or fewer connections than a person who feels socially connected and has a life full of possibility. As such, this concept bears some similarity to the idea of social capital (Putnam, 2001) or social network analysis (Scott, 1988). We use the concept of meshwork here, however, to capture the personal, subjective experience of space through time; of the web of a person's own relationships, memories, activities and actions, as they stretch back through time and project forward into the future. Thus Ingold's concept will enable us to explore the holistic socio-spatial experiences of people experiencing distress in the community.

\subsection{Community spatial interventions: Situating the Walk and Talk group}

The project explored in this paper was a Walk and Talk (WnT) group which has been running weekly for several years in an inner city location in the UK. The group was originally set up by a Clinical Psychologist, but has been peer led for most of its life. Walks are weekly, vary in their focus and location, and offer a regular, informal space in which to walk and talk with others. The group was inspired by Guy Holmes' WnT group in Shropshire, begun when service-users suggested that walking in the countryside may "repair some of the damage done to [them] by toxic environments" (Holmes, 2010: 217). Rather than escaping 'toxic' environments to the respite of the countryside, the urban WnT group instead takes place within the urban spaces in which the participants spend their lives. The peer leaders of the group theme walks around local history and geography, rather than psychological concepts such as mindfulness, which were the original focus of the group when set up by professionals.

As such, this particular group requires a different theoretical approach to the original WnT group. Holmes and Evans (2011) partially located the therapeutic benefit of their original WnT group in the countryside itself, understanding nature as a boundaried place of respite which enables escape from everyday life. These are familiar ideas in the eco-therapy literature, which posits restorative properties in natural landscapes (Gatersleben, 2008, Marselle, Irvine \& Walmer, 2013; Thompson et al., 2011). Such ideas tend to draw on either psychoevolutionary theories that humans find natural environments inherently restful (Ulrich 1983; Ulrich et al., 1991), or 'attention restoration' theories which argue that natural environments 
are full of stimuli high in soft 'fascination' (e.g., leaves moving in a breeze) that effortlessly attract individuals' involuntary attention (Kaplan, 1995).

Indeed, $\mathrm{WnT}$ is not the only mental health intervention to draw a relationship between walking, distress and recovery. In line with the growing move to 'social prescription' and physical exercise as an intervention for mental health (Callaghan, 2004), walking has been posited both as a preventative measure and intervention. There is a body of literature linking walking with positive mental health in the general population (Marselle, et al, 2013) as well as reducing symptoms for those with diagnosed conditions (Carek, Laisbtain \& Carek, 2011; Callaghan, 2004; Pearsall, Smith, Pelosi \& Geddes, 2014; Crone, Smith \& Gough, 2006). Many of these studies draw draw on biochemical and physiological causal mechanisms, which suggest walking is a way to generate 'mood-regulating' neurotransmitters (e.g., monoamine) and lower arousal levels (Crone et al., 2006; Robertson, Robertson, Jepson \& Maxwell, 2012). Social cognitive theories are also frequently used to underpin arguments that walking enhances well-being by boosting feelings of 'self-efficacy' and competence (Crone et al., 2006; Robertson et al., 2012). Overall, both the subjective understandings of participants and the impact of the environment in which walking takes place tend to be overlooked (Crone et al., 2006; Priest, 2007; Soundy, Muhamed, Stubbs, Probst \& Vancampfort, 2014).

Rather than positioning the Walk and Talk group as a form of 'social prescription', we wish instead here to draw attention to the similarity of this group with other community spatial interventions which have emerged in the wake of community care. These include the international Men's Sheds project (Golding, 2008; Hansji, Wilson \& Cordier, 2015), the Dragon Cafe (Thomas \& Rose, 2013; Wheeler, 2005), and Recipes of Life (Shoreditch Trust, 2012). What these diverse projects share is the combination of shared, meaningful activity, reciprocal relationships, and a space for connected relationality described as missing from contemporary community care above. In exploring the experiences of participants in the WnT group, therefore, we expand the analysis of the group's purpose and activities beyond individual physical responses to situate the activity of the walking group within the broader meshworks of the participants' lives.

\section{Empirical approach}

This was a qualitative study, drawing on the ecological ontology outlined in the introduction. Ethical approval for the study was granted from the host university. As well as engaging in formal data collection, the first author attended the group on a weekly basis, for around a year. The observations from this period were not included as data, due to ethical concerns around the consent of members of the group. The purpose of attending was to experience the group in process, as well as build trusting relationships with the group members. Following discussion with the group, it was jointly decided that only the formal interviews would be used as data. This was to respect the confidentiality of those members of the walking group who decided not to take part in the final study. It was thus made clear to participants that they did not have to take part in the data collection, and could withdraw at any time. Several group members declined to be interviewed, which in turn indicates that group members did not feel coerced to take part in formal data collection.

Six participants were recruited for the research. The inclusion criteria were that participants were currently accessing the WnT group and over 18 years old. Participants were between 52 and 71 years old, which reflects the age profile of group members; two participants were female and four were male. Diagnostic information was not directly sought from participants, as this was counter to the ethos of the group, which emphasises participants' shared interests and relationships rather than diagnostic labels. Three of the participants had grown up in London, while another participant emigrated to the UK from Eastern Europe as an adult. Two participants had lived in different parts of England before moving to London as adults. 
A multi-modal qualitative approach was taken to enable a rich exploration of participants' accounts of contexts and their subjective experiences. Two complementary forms of data were gathered: photo production and walk along interviews. Six participants completed the walk along interview and five the photo production interview, meaning that the data set in total consisted of eleven interviews and five sets of photographs. These methodologies were chosen to help facilitate participants' accounts of their material environments, as well as enabling participants have an active role in shaping the narratives produced in the interview, thus minimising the power differential inherent in research (Pink, 2001; Prosser, 1998).

In the photo-production interviews, participants were invited to take photographs of places they felt a connection to, places that they did not feel a connection to, and places that they related to differently since joining WnT. These photographs formed the basis for a later semistructured interview. Visual methods have been argued to help participants to access and articulate spatialised experiences that they may not normally put into words (Prosser, 1998; Rose, 2016). The use of photographs was intended to acknowledge that participants "do not only speak, but experience and view their world in material space" (Reavey \& Johnson, 2013: 299).

Walk-along interviews were also conducted with participants, along a route which they had chosen. Walking is an embodied, multi-sensory experience that can facilitate contact with different memories and feelings (Adams \& Guy, 2007; Ingold \& Vergunst, 2016; Middleton, 2010). Brown and Durrheim (2009) state that mobile interviews, because they are interspersed with visual and aural interruptions, have a situated immediacy that elicits more interactive discussions about contexts. Mobile methods are also argued to facilitate more open, participant-led interviews compared to traditional interview formats, which are arguably more bounded by the socialised interviewer/interviewee positioning (Brown \& Durrheim, 2009; Finlay \& Bowman, 2017). Overall, these methodologies were successful in generating rich accounts of located experiences of the WnT group and everyday life.

\subsection{Analytical approach}

Thematic analysis (TA) (Braun \& Clarke, 2006) was chosen to analyse the data set. In line with other qualitative methodologies, TA is used by researchers to help identify meaningful patterns across data-sets and rich descriptions of phenomena (Fereday \& Muir-Cochrane, 2006). The flexibility of TA enables researchers to acknowledge: "the ways individuals make meaning of their experience, and, in turn, the ways broader social context impinges on those meanings, while retaining focus on the material and other limits of 'reality"' (Braun \& Clarke, 2006: 81).

TA can be conducted in multiple ways. Braun \& Clarke (2006) suggest that themes can be identified either in a 'bottom up' inductive manner or a theoretical 'top down' manner. An inductive TA is driven by the 'raw' data and does not seek to fit it into a "pre-existing coding frame" (Braun \& Clarke, 2006, p.83). A more deductive 'top-down' analysis, however, is usually tied to a pre-established theoretical or analytic area of interest. In the present research, a dual inductive-deductive approach was undertaken (Joffe, 2010). From the outset, the data was approached from a specific ontological stance. Yet, this theoretical orientation did not form a pre-established or fixed coding frame and instead the data were analysed in an immersive way that aimed to remain open to inductive meanings.

The data were read and examined, along with field notes made by the first author after the interviews. Initial codes were generated through systematically coding each transcript manually. Themes were then developed through considering the relationship between codes and possible overarching ideas. To facilitate the identification of themes and sub-themes, mind-maps were created which loosely grouped the codes together. This initial thematic map was reviewed to consider whether the candidate themes were distinctive and adequately captured the data. This process led to certain themes being collapsed and new ones being 
identified. Further interrogation of the themes at this stage was combined with drawing on theoretical concepts in more depth. At this stage the central metaphor of the meshwork was decided upon, leading to the four themes: Fading lines: Fossilised meshworks of loneliness and loss; Therapeutic nodes: Atomized sanctuary and respite in everyday space; Reciprocity and authenticity: Strengthening relational meshworks; Remaking everyday spaces: Expanding meshworks through collectivity.

\section{Life Lines: Expanding and contracting meshworks}

In participants' accounts of both everyday experiences of distress and their participation in the WnT group the group was talked about with warmth and affection, both in terms of the activities carried out and the relationships which had built up over the years of the group's operation. In this analysis, we focus on the spatialised aspects of the experiences of distress, connection, and relationality which were described by participants. In doing so, we draw on Ingold's idea of the 'meshwork' made up by 'lines' of experience, connection, emotion and energy, building up over time. We first analyse the experiences described by participants in their everyday spaces, paying attention to the prevalent experiences of loss and loneliness, followed by the spatial strategies undertaken by participants to counter these experiences of heaviness and loss. We have divided these into themes of 'fading lines' and 'therapeutic nodes'. The second two themes explore the intervention of the WnT group into these everyday spaces, or 'meshworks' as they can be understood as being experienced by participants. Here we discuss the fluid connectivity enabled by the group, and the strengthening, re-activating experiences participants describe when using space differently in their everyday environments.

\section{Fading lines: Fossilised meshworks of loneliness and loss}

Several participants described experiences of missing people, loss and loneliness, as being central to their experiences of their everyday spaces, including both home spaces and neighbourhoods. Participants described meshworks which were weighted backwards towards their pasts, filled with memories of relationally rich lives which contrasted with a more solitary present. They described lives which were in many senses active and moving, where they trod familiar paths through their everyday spaces. Yet they also conveyed an emotional sense of being hindered in the present due to their greater connection with the past. Neil for instance, described how he prefers to "live in the past":

Neil: I don't really enjoy being middle aged, I find it very hard (....) I just prefer the past, that's all (....) And I live near where, my first primary school, it's just off $X$ road and I was happy there. Um, but you know that's how it is for me, nostalgia ... I really do live in the past too much (...) I think nostalgia is a sickness really, isn't it?

Neil here highlights how he prefers to "swim upstream in the flow of experience" (Brown \& Reavey, 2015: 65) towards childhood. His comment that nostalgia is a sickness expresses his unease with how his past and the longing he feels for it envelops his present meshwork so fully. The recursive relationship between his spatialised memories and the discomfort he experiences in his present seems to pull him towards a lost past. Neil describes having easy access to a material world which can generate memories of belonging and relating, through his primary school and other spaces from his childhood. His description is bittersweet, however, as he captures both the ease with which he accesses these rich life experiences, and his feeling that he is missing something by returning there. Jacob similarly described being pulled backwards into his past:

Jacob: Well, I look at it [photograph of home] sad that my wife is not there anymore in the photo, this was a home for two people which we lived together and they think you are an old man who has no wife anymore so you are for the scrapheap, let's get 
rid of him or something, that's how they feel about me (....) In this photo I am showing you a picture of the disturbance of the neighbours and the disturbance in me alone (....) l've lost a whole load of people around me and all in one period of time ... You look at the house and think to yourself, it was a place where I had my life and it's gone.

Jacob's house here seems to encapsulate for him the relative relational emptiness of his present compared to the past with his wife. He describes being located in a broader hostile relational environment as an older person being positioned by his neighbours as 'on the scrapheap'. Like Neil, Jacob's narrative suggests that in the absence of nourishing interactions with others, the 'lines of wayfaring' in his home have become stagnant, reaching back to a past which cannot fully be touched. Ingold's $(2011 ; 2015)$ theory of lines emphasises that humans are continually moving and growing, while also arguing that "their growth is conditioned by the presence and action of others, they grow one another'" (2015: 120). Ingold thus proposes that as we move through life, acting and relating with others, we form knots and threads which trail behind us, and hence over time our meshworks can become richer, enfolded with new lines and knots. In Neil's case, constant retreading of his past meshwork seems to be impeding the formation of new lines and knots; the relative paucity of his present meshwork then again draws him back emotionally, and spatially, to the comparative richness of the past.

The experience of missing people who were no longer present because of death or separation was one of the strongest themes in the interviews. Yet as both Neil and Jacob encapsulate above, the residual materiality of the past was also woven into the present, through the objects and spaces surrounding them. Jacob continues to live in the house that he shared with his wife; Neil lives in a neighbourhood with the school in which he feels he lived a richer life. It is in this sense that we use the term 'fossilised': fossils carry a 'vibrant materiality' (Bennett, 2010), conjuring suggestions of a rich and fluid past, captured in static form. Within Neil and Jacob's meshworks, the material traces of past rich relationality remain, calling them back to the past. We hence want to capture the paradox which many participants described in trying to negotiate ongoing lives which were strongly shaped by loss. As Ingold highlights, living is characterized by inevitable growth and movement. For our participants, however, this sense of movement could feel as though they were moving further away from a relationally richer life, located in the past. Jacob, for instance, described how grief for his wife was embedded in the objects and spaces of his home:

Jacob: Oh it makes me sad. Very, very sad. I can't forget her, I haven't touched any of her things. If I touch her things I feel I can, if I throw some of the things out I feel I'm throwing her away. I'm admitting to the ... loneliness, to the loss. You know you don't want to admit to the loss, it's like burying somebody, when you bury somebody, the Jewish law we bury very, very quickly, straightaway and it feels an immense loss (....) I feel sometimes like turning around and talking to her. I can just feel her sometimes.

Jacob's experience of his home space is here described as being imbued with grief, loss and loneliness. There is a sense that Jacob's home environment has become stuck following the death of his wife and dominated by feelings of sadness, much of which is focused on the objects his wife left in the home. The objects here can be seen to form a fossilised version of the relational knots and lines that Jacob formed with his wife; just like a fossil, something here is retained of their past relational shape, but that relationship can no longer move or grow. The 'thing-power' (Bennett, 2010) of these objects in keeping a fossilised version of Jacob's marriage alive for him, can be seen as captured in his heart breaking equation of moving or throwing away objects relating to his wife to "throwing her away".

Marie similarly described how feelings of loneliness pervaded her experiences of her everyday spaces, here talking about her neighbourhood rather than home:

Interviewer: How do you feel when walking around your local area? 
Marie: When I'm alone? (Interviewer: Yeah) Sad. Sad, quite sad. I have a lot of um suppressed feelings (....) Oh, my reasons are, it's not self-pity cause we were on the subject so l'll say it, otherwise I wouldn't say to anyone but my reasons are obviously cause I seem to have lost so many people in a short space of time that I was so close with, that I look around now and I think, I really you know, I kind of don't have anyone, people say to me "oh, you've got family, you've got your kids" etc, etc and I say "do you know how lonely I am?" (....) It doesn't always mean because you have family that you're not lonely, sometimes you can be on your own and not be lonely if that makes sense? (....) I don't have my mum and dad anymore (....) I, I lost my husband as I say, so I had that to cope with...

Marie here describes experiencing a profound sense of loneliness when she moves through her local area. In this account, her physical environment is imbued with relational memories which appear to act like a double-edged sword, stabilising meaningful past relationships (Brown \& Reavey, 2015; Tucker, 2013; Serres, 1995) while simultaneously highlighting the absence of people she has lost. For instance, although she lives with family members, the loss of people like her husband, who previously inhabited her home, fosters an overriding sense of being completely alone there:

Marie: Like in this flat I think to myself, I'm the only one left here now (....)

Now it's just me. It's literally gone down to me.

The loneliness often highlighted as central to experiences of distress, is here accounted for as being embedded in her everyday spaces, intensifying in particular places. Across the interviews, therefore, were descriptions of experiences of loss and of feeling like possibilities for future relationships and activity were stifled and reduced. In thinking of these experiences as 'meshworks', made up by 'lines' of action, energy and experience, we can see that the participants describe meshworks which can be seen as fossilised, weighed down by the losses and memories of the past. The heaviness of past relationships and the tangible non-presence of lost others embedded into everyday spaces here can again be understood as contributing to these feelings of a more hollow, solitary and less connected present life.

\section{Therapeutic nodes: Atomised sanctuary and respite in everyday space}

Alongside the picture of fossilised and loss-imbued everyday spaces, participants also described using other spaces in their meshworks as spaces of sanctuary and respite. These spaces were different for each participant, and help to highlight the creativity of participants in managing their own agency and emotional experiences. Robert, for instance, discussed visiting the park:

\section{[Figure One about here]}

Robert: It's nice to walk round the park. No particular reason why. I find it comfortable when I'm feeling depressed or a bit you know, so I find a walk in the park does me good. It takes the pressure off my head and it gives me a chance to think, especially like one o'clock in the morning I come out and walk, there's no one looking at you, no one watching you (....) l've always done it even when I first became unwell I went to, often when I was living in a hostel I used to go to $X$ Park and walk round there for hours.

Robert here describes visiting the park as a way to experience feeling lighter, more active and agentic than within his home environment. As McGrath \& Reavey (2015) have argued, in some states of distress or feeling, outside spaces can provide a sense of fluidity and expansiveness which can help to dissipate intense or overwhelming emotional experiences. Robert here explains that walking in the park "takes the pressure" off his head, which can be similarly understood as describing providing him with the ability to relieve the compressing force of his emotions, to stretch out. This use of the space of the park as a place of respite is described 
as being habitual, transferred between different specific park spaces depending on where he is living at the time. In Ingold's (2012) terms, these repeated circumambulatory movements across different specific spaces, can be seen as creating trails or lines within his meshwork which Robert can inhabit, and return to when his emotions threaten to overwhelm other spaces.

Other participants described different spaces as similarly facilitating a calming sense of being at ease in the world, what we are here calling 'therapeutic nodes'. Sara, for instance, describes a local place where she can sit alone and be a part of the environment around her. The focal point is a number of palm trees within a busy square by a main road:

[Figure Two about here]

Sara: Many times I'm coming from my house just to see them [palm trees] Just to see them, in the summertime I stay around the way.

Interviewer: And can you tell me a bit about how you feel when you are there?

Sara: I feel so nice because it's my friends, it's my special time when I see them. Just watching them and stay underneath of them around the way, just watching them and looking and drinking coffee and tea and just watching them.

Sara describes routinely walking to the palm trees, as she enjoys looking at them while drinking tea or coffee. This kind of everyday practice can be understood as illustrating Sara's ability to 'rewrite' part of the city (De Certeau, 1984) and create a personal grounding point, a 'therapeutic node', in her meshwork. Sara describes the trees as her "friends" as if to emphasise the importance of the spatial connection they represent, and in contrast to the material reminders of loss described in the first section of this analysis. The part of the city the trees are in is crowded, but Sara's account can be understood as describing how she has shaped a peaceful place where she can repeatedly generate "nice" feelings, through her habitual movements. She refers to the time she spends by the trees as "my special time" [emphasis added], which also suggests that she has a valuable sense of control over her experiences there.

These accounts demonstrate the ways in which participants described actively curating space to help them negotiate difficult emotions and counter some of the heavy, fossilised experiences of space described in the previous section. It is notable, however, that these accounts are of atomised and individual strategies. Whilst participants describe being able to seek out therapeutic nodes in space, these are not described as expanding their relational meshworks in a broader sense. This can be seen as further indicating the paucity of both community and mental health spaces in facilitating relational expansion and connection.

\section{Reciprocity and authenticity: Strengthening relational meshworks}

The accounts which participants gave of their experiences of the WnT group can be seen to stand in comparison to these experiences of their everyday spaces as fossilised and atomised. In contrast, the experiences which participants described as part of participation in WnT can be viewed as ones which opened, expanded and strengthened their meshworks, their lines of connection to place, themselves, others, and future possibilities. A particular aspect of the group that facilitated this holistic process was the opportunities it provided to form meaningful connections with others:

Marie: And I remember (....) being so happy and elated and it might sound strange to people but I was kind of meeting up with people again and getting friends and I thought this is nice, I'm going to come back to this (....) It was almost like I done woooh some big skip... 
Robert: Yeah, when you live on your own you get bored sometimes, you don't wanna cook, you don't wanna get up, you don't want to do things, so it's nice having a bit of social time together (....) it's nice, the socialising.

Both Marie and Robert's comments suggest that an important facet of the WnT group was feeling energised by the interactions they have with others. Marie conveys the embodied activating force her feelings of happiness have by comparing them to a "big skip". While Robert, by describing how difficult it can be to feel motivated when living alone, illustrates the sense of vitality he gains from being around others and having "social time". Such comments show that participants valued being able to access a space where they could both affect, and be affected by others, in the here and now. The stifling feelings of relational loss described above as enfolding many everyday spaces can be understood as being dislodged during WnT, through social connection with others.

The particular quality of the relationships described in the WnT group was also described as important. For instance, Jacob described how speaking with another WnT member about the grief he experienced after his wife's death developed a sense that his pain was not simply understood, but felt by another person:

Jacob: They [WnT members] understand the loneliness. Take X, she said to me I understand (....) she grabs a pillow sometimes, she was telling me about herself, now a Social Worker would never tell you about herself would she? X has also lost her husband, she grabs a pillow because she still feels the lack of the love of her husband (....) There are very few social services people who've got the heart is inside you like $X(. .$.$) Social services can understand your pain but the person who is your friend feels$ your pain. This one understands it and this one feels it, feels your pain.

Jacob here describes the difference between a professional relationship and a reciprocal, authentic sense of connection he experienced at $\mathrm{WnT}$, which is based on shared experience and emotional reciprocity. Multiple authors writing about peer support (Repper \& Carter, 2011) and user led services (Campbell, 2005) have highlighted that horizontal and reciprocal relationships based on shared experience rather than professional expertise can be particularly beneficial for those experiencing distress. Jacob's account here particularly highlights how a shared feeling, as a different form of knowing to that of professional knowledge, fostered a more authentic sense of shared connectivity. This account also contrasts with the profound isolation that was evoked in Jacob's descriptions of his home space, where his lifelines seemed blocked from knotting with those of others in the everyday landscapes around him. In this sense, the authentic connection and relationality described here can be understood as strengthening Jacob's meshwork, knotting his emotional life more closely with those in the present, and hence helping to reshape his painful relationship with his past.

\section{Remaking everyday spaces: Revitalising meshworks through collectivity}

This sense of shared connectivity, a strengthened and revitalised meshwork, was also described as enabling the exploration of new physical spaces, or the reshaping of relationships with everyday spaces. As Sara commented:

Interviewer: So, if you go into a new area and you are walking around.. (Sara: I don't like) You don't like?

Sara: Mmm hmm

Interviewer: Do you ever do that?

Sara: I do sometimes, but no, I don't like.

Interviewer: Okay, and when you go a new area with the group does that feel different?

Sara: With the group I never mind. When I'm with the group, l've got people, we look like family, I never mind. But on my own I don't like (....) With the group you feel more confident, you are together.

Sara explains that when she is alone she does not like moving beyond the familiar pathways in her everyday spaces, conveying a sense of a meshwork that has contracted and become 
rigid over time. Her comments that "with the group I never mind" and "you feel more confident", indicate that trying out unfamiliar routes with WnT feels easier. Sara's description that the group looks like a "family" is interesting, as the WnT members look diverse in their appearance. It could be that Sara chooses the word "family" to highlight the strength WnT members have when they come together. Altogether, this emphasis on how being with others bolsters her ability to actively forge new trails, conveys the powerful forms of mutual support people can gain from making interpersonal connections (Afuape \& Hughes, 2016; Moane, 2011). By moving together, they are able to expand their meshworks and 'wayfare' together into new areas.

Jacob explicitly names the collective power WnT members have when he describes their visit to the house of Parliament:

Jacob: The group has got a power, it's a part of [local area] we got into parliament, the MP took us around, you know what I mean? We went into the chambers and everything else, of course we did, we wouldn't have got into such a place without it.

This account emphasises a "power" which the group has to move into places, which are normally difficult to access; Jacob expresses that "without" this power they would never have been able to enter certain spaces, emphasises that collectively the group are more powerful than as individuals. Participants also discussed about how much they enjoy expanding their territories when they walk with the group, describing visiting different places that are stimulating and break the monotony of everyday life:

Marie: I never really entered the canal before, before the groups I never used to use the canal on a walk (....) X [one of the WnT leaders] has took us to so many places that we've been like, it's been really, he's enlightened me in lots of things I should have know, cause l've been all my life round here, but never along the canal (....) My husband used to say, 'Oh, you go past [local area] and Marie falls off the edge of the world!' [laughs]

Marie's reflection that she is now going over "the edge of the world" can be seen as indicating that participation in the group enables her to widen her territories, and extend beyond the usual limits of her meshwork. This expansion also can be seen to remain outside of the group; later in her account Marie describes how she now enjoys walking along the canal alone finding it functions as an additional 'therapeutic node'. The path that the group has collectively forged through the space of the canal can be seen to have left a line which Marie now finds easier to retread, and thus weave more firmly into her own personal meshwork.

Some participants also described how visiting and exploring new places with the group helps to alleviate distress that they experience in their personal territories:

Jacob: It [WnT] makes me feel, it's a different surrounding. You go out of the house (....) which is very important every day to get out of the house and not spend all day brewing about your life, that you're sad, you're on your own (....) When I'm in the house I'm really sad, I like to get out on to the waterways with the boats and everything else (....) It gives you a different em ... I don't think it makes you forget, it just breaks the monotony of just thinking all the time of the emptiness of the thing.

Sara: So, now when I walk with these people I'm more happy when I walk myself. Before, I was more upset, every time the same thing but now I wait for people to meet. My friends.

Sara, who earlier, depicted the comforting familiarity of sameness, points out here that unrelenting sameness can however cause feelings of distress. She describes feeling "more happy" walking her usual routes now that she knows each week she will have the opportunity to move beyond them with friends. While Jacob describes how being with WnT breaks the emotionally oppressive monotony of "just thinking all the time of the emptiness of the thing". The "thing" here could refer to the fossilised meshworks explored in the first section. $\mathrm{He}$ highlights that moving to "different surroundings" can help to dissipate difficult thoughts and feelings, which 'brew' and saturate his experience when he is at home. The meaningful connections between group members can therefore be seen as creating powerful 'life lines' 
that engender reciprocal forms of support and exploratory movements through everyday and new landscapes.

\section{Beyond endorphins: Walking groups, relationality and the meshwork}

In this paper we have discussed the experiences of participants in an urban WnT group, using the concept of 'meshwork' to capture the complex interrelations between social, spatial and personal relationships which make up each individual's lived, situated experience of distress. This paper demonstrates the potential richness of Ingold's $(2011 ; 2015)$ work for contributing to our understanding of mental distress as holistic, embodied and materially embedded experiences. The meshwork perspective encourages attention to the whole system of a person's life: their past, their environment, and most richly, how they move, grow and forge paths with others through the substances of the world.

One of the strengths of Ingold's $(2011 ; 2015)$ approach is thus the way that the concept of the meshwork captures a holistic picture of a whole person in process, moving through space and time. Our participants' accounts of fossilised and residual materialities which tie them to the past emphasise the richness, complexity and specificity of people's distress. The meaning of past events and relationships can here be seen to continue to shape and infuse present lives and future possibilities. Bringing this richness to the forefront of thinking about distress orientates us to consider the whole context of people's experiences, as opposed to decontextualised symptoms. In contrast to some sociological or epidemiological approaches, however, Ingold's meshworks also retain a focus on the person and the richness of subjectivity. This links to approaches such as community psychology (Orford, 2008) and sociomaterial theories (Smail, 2005) which similarly emphasise the role of multiple layers of social and material contexts in people's experiences of distress and wellbeing. It is this orientation to both context and the complexity of individual emotional landscapes which is a key strength of Ingold's particular ecological approach. This is not only a theoretical observation. The first author has found that when undertaking clinical work with individuals, facilitating conversations about everyday environments can help to open new perspectives on difficult experiences. Locating distressing experiences can therefore be a useful tool in helping clients and practitioners to think more holistically about the causes and sources of their distress.

Relationships are at the core of Ingold's $(2011 ; 2015)$ ideas, and it can be seen in this study that relationships - past, present, future, human and material - were brought forward as central to the lives of participants. In contemporary mental health services, relationships, particularly long lasting, relationships which knot together in meaningful ways, have been long sidelined (Chase, 2011). What this study, and the wider ecological perspective therefore points to, is an agenda for placing relationships at the centre of understanding mental distress and as the source of recovery. Where relationships are emphasized in mental health, these are often limited to the familial and intimate (Smail, 1987; 2005). This research also points to the importance of community and neighbourhood in structuring and shaping people's experiences of distress and recovery. The meshwork perspective enables us to look at these multiple and shifting relational contexts as both fluid and interconnected, all shaping the meshwork of the individual. As discussed in the introduction, there is a move in mental health services towards social prescription, including referring people for activities such as exercise (Callaghan, 2004). What this research highlights is the importance of both collectivity and meaning making in activity based mental health interventions. While much of the research on exercise and activity focuses on the individual biomedical impacts, this research instead highlights that the most crucial experiences in the walking group were not physical, but instead its role in fostering feelings of growth, connection and belonging. The findings in this study, however, also indicate that if group interventions are to facilitate sustained social support, they perhaps need to be detached from the time-limited and goal oriented templates that currently dominate services (Chase, 2011; Holmes, 2010; Lees, 2016; Moloney, 2013). Participants, like those in Holmes (2010) and Priest's (2007) research, valued having an informal, ongoing space that provided opportunities to get to know people over time. This research therefore supports other interventions such as Men's Sheds (Golding, 2008) and the Dragon Café, which prioritise the creation of a safe and creative relational space for engaging in shared, meaningful activity, above technical therapeutic interventions. As argued above, both 
collectivity and the kind of long term, authentic relationality described in the group have been eroded in contemporary UK mental health services. As Chase (2011) argues, mental health services under 'social inclusion' are increasingly focused on 'bridging' rather than 'bonding' activities mainly, as McGrath \& Reavey (2016) argue, delivered in individualised, time limited and professionally led manner. Multiple authors have pointed out the loss of long term, meaningful relationships in mental health care as services have moved to individualised models, away from day provision in day centres or drop in services (Pilgrim \& Ramon, 2009). Yet here, these very relational forms are what we argue enable the participants in the WnT group to build the strength to forge new life lines and expand their meshworks. This is not through delivering a technical mental health intervention, but through building human connection, needed for the 'true independence' of a connected and meaningful life.

\section{References}

Adams, M., \& Guy, S. (2007). Editorial: Senses and the city. The Senses and Society, 2(2), 133-136.

Afuape, T., \& Hughes, G. (2016). Historical development of liberation practices. In T. Afuape \& G. Hughes (Eds.), Liberation practices: Towards emotional wellbeing through dialogue (pp. 27-36). Abingdon: Routledge.

Bloomfield, B. P., McLean, C. (2003). Beyond the walls of the asylum: information and organization in the provision of community mental health services, Information and Organisation, 13 (1), 53-84.

Braun, V., Clarke, V. (2006). Using thematic analysis in psychology, Qualitative Research in Psychology, 3, 77-101.

Brown. L., \& Durrheim, K. (2009). Different kinds of knowing: Generating qualitative data through mobile interviewing. Qualitative Inquiry 15(5), 911-930.

Brown, S. D., Cromby, J., Harper, D. J., Johnson, K., \& Reavey, P. (2011). Researching "experience": Embodiment, methodology, process. Theory \& Psychology, 21(4), 493-515.

Brown, S., \& Reavey, P. (2015). Vital memory and affect: Living with a difficult past. Routledge.

Brown, S. D., Stenner, P. (2009). Psychology without foundations: History, philosophy and psychosocial theory. London: Sage.

Callaghan, P. (2004). Exercise: a neglected intervention in mental health care? Journal of Psychiatric and Mental Health Nursing, 11(4), 476-483

Capra, F., \& Luisi, P. L. (2014). The systems view of life: A unifying vision. Cambridge University Press.

Carek, P. J., Laibstain, S. E., \& Carek, S. M. (2011). Exercise for the treatment of depression and anxiety. The International Journal of Psychiatry in Medicine, 41(1), 15-28.

Crone, D., Smith, A., \& Gough, B. (2006). The physical activity and mental health relationship: A contemporary perspective from qualitative research. Acta Univ Palacki Olomuc Gymn, 36, 29-35.

Curtis, S. (2010). Space, place and mental health. Ashgate Publishing, Ltd.

Davidson, J. (2000). 'the world getting smaller': women, agoraphobia and bodily boundaries, Area, 32 (1), 31-40.

De Certeau. (1984/2011). The Practice of Everyday Life. London: University of California Press.

Estroff, S. (1981). Making it crazy: An ethnography of psychiatric clients in an American community. California: California University Press.

Gatersleben, B. (2008). Humans and nature: Ten useful findings from environmental psychology research. Counselling Psychology Review, 23(2), 24-34.

Gibson, J. J. (2014). The ecological approach to visual perception: classic edition. Psychology Press.

Goffman, E. (1963). Behaviour in public places: Notes on the social organisation of gatherings. New York: The Free Press. 
Golding, B. (2008). Researching Men's Sheds in Community Contexts in Australia: What Does it Suggest about Adult Education for Older Men? Journal of Adult and Continuing Education, 14(1), 17-33.

Hansji, N. L., Wilson, N. J., \& Cordier, R. (2015). Men's Sheds: enabling environments for Australian men living with and without long-term disabilities. Health \& Social Care in the Community, 23(3), 272-281.

Hawkley, L. C., \& Cacioppo, J. T. (2010). Loneliness Matters: A Theoretical and Empirical Review of Consequences and Mechanisms. Annals of Behavioral Medicine, 40(2), 218-227.

Holmes, G. (2010). Psychology in the real world: Community-based groupwork. Ross-onWye: PCCs Books.

Holmes, G., \& Evans, N. (2011, July). Walk and talk. Paper presented at the 1st International Conference on Multi-Dimensional Aspects of Wellbeing, University of Central England. Retrieved 9 April 2015.

Fereday, J., \& Muir-Cochrane, E. (2006). Demonstrating rigor using thematic analysis: A hybrid approach of inductive and deductive coding and theme development. International Journal of Qualitative Methods, 5(1), 80-92.

Finlay, J. M., \& Bowman, J. A. (2017). Geographies on the Move: A Practical and Theoretical Approach to the Mobile Interview. The Professional Geographer, 69(2), 263-274.

Ingold, T. (1993). The temporality of the landscape. World Archaeology, 25(2), 152-174.

Ingold, T. (2011). Being alive: Essays on movement, knowledge and description. Abingdon: Routledge.

Ingold, T. (2015). The life of lines. Abingdon: Routledge.

Ingold, T., \& Vergunst, J. L. (2016). Introduction. In T.Ingold \& J.L. Vergunst (Eds.), Ways of walking: Ethnography and practice on foot (pp. 1-19). Abingdon: Routledge.

Joffe, H. (2012). Thematic analysis. In D.Harper \& A.R. Thompson (Eds.), Qualitative Research Methods in Mental Health and

Psychotherapy: A Guide for Students and Practitioners (pp. 209-223). Chichester: John Wiley \& Sons.

Kaplan, S. (1995). The restorative benefits of nature: Toward an integrative framework. Journal of Environmental Psychology, 15(3), 169-182.

Kelly, J. G. (2006). Becoming ecological: An expedition into community psychology. Oxford University Press.

Knowles, C. (2000). Bedlam on the streets. London: Routledge.

Levitas, R. (2006). The concept and measurement of social exclusion. Poverty and Social Exclusion in Britain. The Millennium Survey, Policy Press, Bristol, 123-60.

Lewin, K. (2013). Principles of topological psychology. Read Books Ltd.

Marselle, M. R., Irvine, K. N., \& Warber, S. L. (2013). Walking for well-being: Are group walks in certain types of natural environments better for well-being than group walks in urban environments?. International Journal of Environmental Research and Public Health, 10(11), 5603-5628.

Middleton, J. (2010). Sense and the city: Exploring the embodied geographies of urban walking. Social \& Cultural Geography, 11(6), 575-596

Moloney, P. (2013). The therapy industry: The irresistible rise of the talking cure, and why it doesn't work. London: Pluto.

Mclnnis, G. J., \& White, J. H. (2001). A phenomenological exploration of loneliness in the older adult. Archives of Psychiatric Nursing, 15(3), 128-139. https://doi.org/10.1053/apnu.2001.2375

McGrath, L., \& Reavey, P. (2016). "Zip me up, and cool me down": Molar narratives and molecular intensities in "helicopter" mental health services. Health \& Place, 38, 6169. 
McGrath, L., Reavey, P., \& Brown, S. D. (2008). The scenes and spaces of anxiety: Embodied expressions of distress in public and private fora. Emotion, Space and Society, 1(1), 56-64.

McGrath, L., \& Reavey, P. (2013). Heterotopias of control: Placing the material in experiences of mental health service use and community living. Health \& Place, 22, 123-131.

Psychology, 3(2), 77-101.

Moriarty, J. et al (2007). Practice guide: the participation of adult service users, including older people, in developing social care. London: Social Care Institute for Excellence.

Orford, J. (2008). Community psychology: Challenges, controversies and emerging consensus. Chichester: John Wiley \& Sons \& Sons.

Parr, H. (2008). Mental health and social space: Towards inclusive geographies? Oxford: Blackwall.

Pearsall, R., Smith, D. J., Pelosi, A., \& Geddes, J. (2014). Exercise therapy in adults with serious mental illness: A systematic review and meta-analysis. BMC Psychiatry, 14(1), 117.

Pilgrim, D., Rogers, A., \& Bentall, R. (2009). The centrality of personal relationships in the creation and amelioration of mental health problems: the current interdisciplinary case. Health, 13(2), 235-254.

Pinfold, V. (2000). 'Building up safe havens... all around the world': users' experiences of living in the community with mental health problems, Health \& Place, 6 (3), 201212.

Putnam, R. D. (2001). Bowling alone: The collapse and revival of American community. Simon and Schuster.

Reavey, P. (2012). Visual methods in psychology: Using and interpreting images in qualitative research. Routledge. Rose, G. (2016). Visual methodologies: An introduction to researching with visual materials. Sage.

Repper, J., \& Carter, T. (2010). Using personal experience to support others with similar difficulties: A review of the literature on mental health in peer support services. University of Nottingham/Together, Nottingham.

Robertson, R., Robertson, A., Jepson, R., \& Maxwell, M. (2012). Walking for depression or depressive symptoms: A systematic review and meta-analysis. Mental Health and Physical Activity, 5(1), 66-75.

Rogers, A., \& Pilgrim, D. (2002). Mental health and inequality. Palgrave Macmillan.

Rogers, A., \& Pilgrim, D. (2014). A sociology of mental health and illness. McGraw-Hill Education (UK).

Rose, G. (2016). Visual methodologies: An introduction to researching with visual materials. London: Sage.

Sayce, L. (2000). From psychiatric patient to citizen: Overcoming discrimination and social exclusion. Basingstoke: Macmillan.

Scott, J. (1988). Social network analysis. Sociology, 22(1), 109-127.

Silva, M. J. D., McKenzie, K., Harpham, T., \& Huttly, S. R. A. (2005). Social capital and mental illness: a systematic review. Journal of Epidemiology \& Community Health, 59(8), 619-627.

Smail, D. (1987/2015). Taking care: An alternative to therapy. London: Karnac Books.

Smail, D. (2005). Power, interest and psychology: Elements of a social materialist understanding of distress. Ross-On-Wye: PCCS Books.

Smith, L.-A., \& Tucker, I. (2015). "Mad, Bad and Dangerous to Know": The pervasive sociomedical and spatial coding of mental health day centres. Emotion, Space and Society, 14, 3-9.

Soundy, A., Muhamed, A., Stubbs, B., Probst, M., \& Vancampfort, D. (2014). The benefits of walking for individuals with schizophrenia spectrum disorders: A systematic review. International Journal of Therapy and Rehabilitation, 21(9), 410-20.

Shoreditch Trust. (2012). Recipes of Life. London: Shoreditch Trust. 
Taylor, B. (2014). The Last Asylum. London: Penguin.

Taylor, C. B., Sallis, J. F., \& Needle, R. (1985). The relation of physical activity and exercise to mental health. Public Health Reports, 100(2), 195.

Thomas, C., \& Rose, D. (2013). Evaluation of the Dragon Café. Report to The SLAM Charitable Trustees, London.

Thompson Coon, J., Boddy, K., Stein, K., Whear, R., Barton, J., \& Depledge, M. H. (2011). Does participating in physical activity in outdoor natural environments have a greater effect on physical and mental wellbeing than physical activity indoors? A systematic review. Environmental Science \& Technology, 45(5), 1761-1772.

Tucker, I. (2010). Mental health service user territories: enacting "safe spaces" in the community, Health, 14(4), 434-48.

Tucker, I (2013). The spatial anticipation of the future in the homes of mental health service users. Outlines. Critical Practice Studies, 14(1).

Ulrich, R. S. (1983). Aesthetic and affective response to natural environment. In J.Altman \& F. Wohlwill (Eds.), Behavior and the natural environment: Advances in theory and research, vol.6. (pp. 85-125). New York, Plenum.

Ulrich, R. S., Simons, R. F., Losito, B. D., Fiorito, E., Miles, M. A., \& Zelson, M. (1991). Stress recovery during exposure to natural and urban environments. Journal of Environmental Psychology, 11(3), 201-230.

Warner, R. (2000). The environment of schizophrenia. London: Brunner-Routledge.

Wickham, S., Shryane, N., Lyons, M., Dickins, T., \& Bentall, R. (2014). Why does relative deprivation affect mental health? The role of justice, trust and social rank in psychological wellbeing and paranoid ideation. Journal of Public Mental Health, 13(2), 114-126.

Whitehead, A. N. (1978 [1929]). Process and reality. New York: The Free Press.

Figures

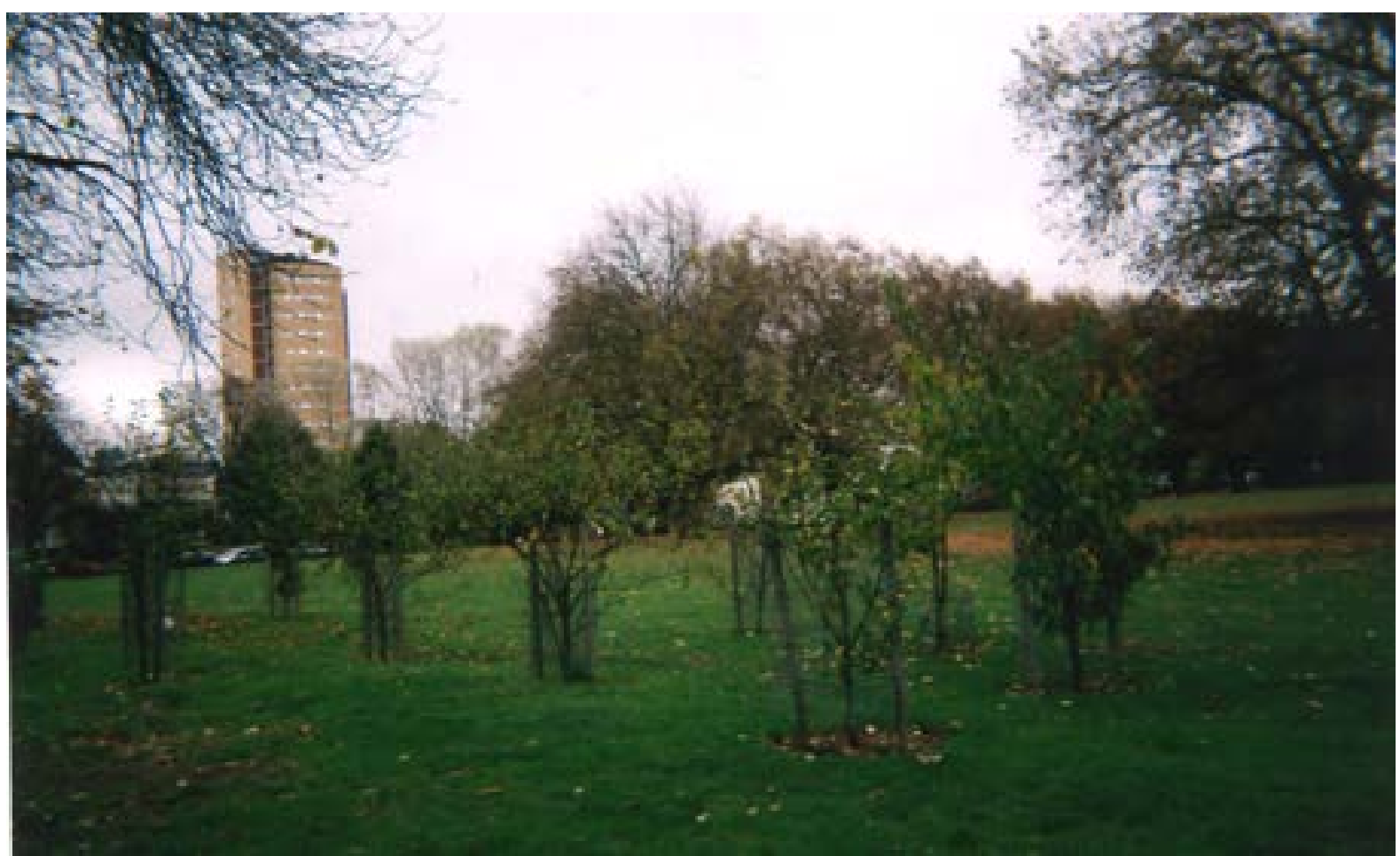


Figure One: Robert's picture of the park

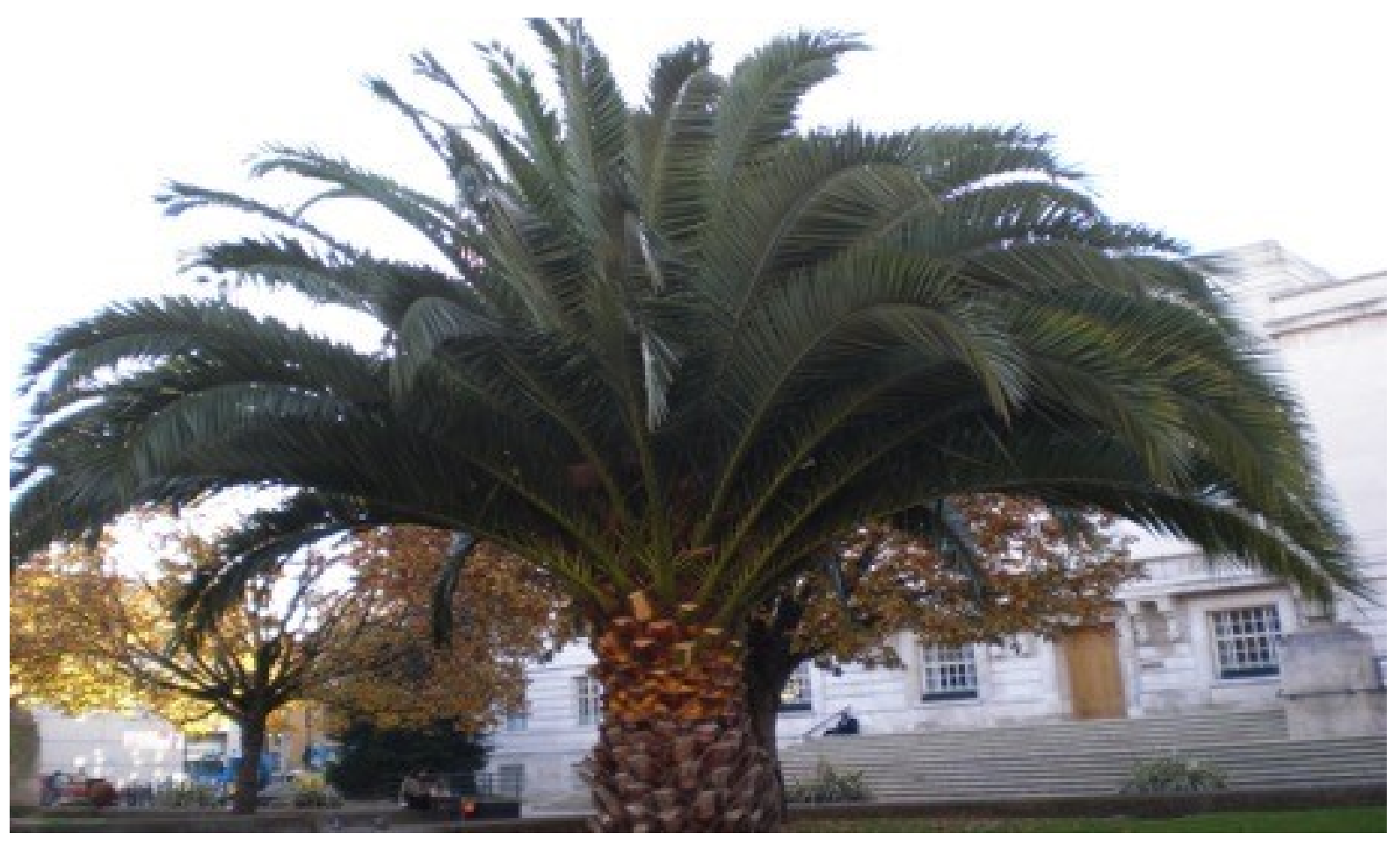

Figure Two: Sara's picture of the palm trees 